\title{
Regional Knowledge Flows and Innovation Policy: A Dynamic Representation
}

\author{
UGO FRATESI \\ Politecnico di Milano, DABC, Piazza Leonardo da Vinci, 32, I-20133 Milan, Italy. Email: ngo.fratesi@polimi.it
}

FRATESI U. Regional knowledge flows and innovation policy: a dynamic representation, Regional Studies. This paper presents a tool to study ex-ante the effects of innovation policy on regional growth and income. It uses a dynamic evolutionary simulation approach and presents a model able to represent the flows of knowledge within and between regions. The model is unique but can be customized to represent different regional innovation modes. The model is calibrated with data of the average European Union NUTS-2 region, and is used to show the different impacts of various policy options, and the different impacts of the same policies in different regions, providing evidence in favour of regionally tailored, place-based approaches. Calibrating the model, through fieldwork, on an actual region will eventually allow ex-ante estimations of actual policy impacts to be produced.

Regional innovation policy Dynamic models Knowledge flows

FRATESI U. 区域知识流动和创新政策: 一个动态的再现, 区域研究。本文呈现一个事前研究创新政策对区域成长和 所得的影响之工具。本文运用动态演化模拟方法, 并呈现一个能够再现区域中和区域间的知识流动的模型。该模型 是特殊的, 但亦能客製化以再现不同的区域创新模式。该模型以欧盟一般NUTS-2层级的区域数据测定之, 并用来 展现各种政策选项的不同影响，以及同一政策在不同区域的不同影响，提供了支持为特定区域量身定做、根据地方 的方法之证据。透过田野工作，根据一个真实的区域测定该模型，最终得以生产实际政策影响的事前评估。

\section{区域创新政策 动态模型 知识流动}

FRATESI U. Les flux de connaissances et la politique d'innovation régionaux: une représentation dynamique, Regional Studies. Cet article présente un outil qui permet d'étudier ex-ante les effets de la politique d'innovation sur la croissance et le revenu régionaux. On se sert d'une simulation évolutive dynamique et présente un modèle capable de représenter les flux de connaissances à la fois intra et interrégionaux. Le modèle est unique mais on peut l'adapter afin de représenter divers modes d'innovation régionale. Le modèle est calibré avec des données sur la région type NUTS-2 de l'Union européenne et sert à montrer les différents impacts des diverses options politiques, et les différents impacts des mêmes politiques menées dans des différentes régions, ce qui a fourni des résultats en faveur des approches régionales faites sur mesure et adaptées au milieu. À partir du travail sur le terrain, calibrer le modèle sur la base d'une région réelle permettra au fur et à mesure de produire des estimations ex ante des impacts politiques réels.

Politique d'innovation régionale Modèles dynamiques Flux de connaissances

Fratesi U. Regionale Wissensströme und Innovationspolitik: eine dynamische Darstellung, Regional Studies. In diesem Beitrag wird ein Instrument zur Vorabschätzung der Auswirkungen der Innovationspolitik auf das regionale Wachstum und Einkommen vorgestellt. Hierfür kommt ein dynamischer evolutionärer Simulationsansatz zum Einsatz, und es wird ein Modell zur Darstellung der Wissensströme innerhalb einer Region sowie zwischen Regionen vorgestellt. Dieses Modell ist spezifisch, lässt sich aber zur Darstellung verschiedener regionaler Innovationsweisen anpassen. Das Modell wird anhand von Daten der durchschnittlichen NUTS-2-Region in der Europäischen Union kalibriert und dient zur Verdeutlichung der unterschiedlichen Auswirkungen verschiedener politischer Optionen sowie der unterschiedlichen Auswirkungen derselben Politiken in verschiedenen Regionen, was Belege zugunsten von regional zugeschnittenen, ortsbasierten Ansätzen liefert. Eine Kalibration des Modells mithilfe von Feldarbeit in einer tatsächlichen Region ermöglicht langfristig eine Vorabschätzung der tatsächlichen politischen Auswirkungen.

Regionale Innovationspolitik Dynamische Modelle Wissensströme

Fratesi U. Flujos de conocimiento regional y política de innovación: una representación dinámica, Regional Studies. En este artículo se presenta una herramienta para analizar de forma ex-ante los efectos de la política de innovación en el crecimiento y los ingresos regionales. Se utiliza un enfoque de simulación dinámico evolutivo y se presenta un modelo capaz de representar los flujos de conocimiento entre las regiones y dentro de ellas. Este modelo es único pero puede adaptarse para representar los diferentes modos de innovación regional. El modelo se calibra a partir de datos sobre la región media NUTS-2 de la Unión Europea, y se utiliza para mostrar los distintos efectos de las diferentes opciones políticas, así como los distintos efectos de las

This is an Accepted Manuscript version of the following article, accepted for publication in Regional Studies, 2015, 49:11, 1859-1872 (http:// dx.doi.org/10.1080/00343404.2015.1068930). It is deposited under the terms of the Creative Commons Attribution-NonCommercial License (http://creativecommons.org/licenses/by-nc/4.0/), which permits non-commercial re-use, distribution, and reproduction in any medium, provided the original work is properly cited 
mismas políticas en regiones diferentes aportando pruebas a favor de enfoques regionalmente adaptados en lugares determinados. Calibrar el modelo mediante un trabajo de campo en una región determinada permitirá a largo plazo hacer estimaciones ex-ante de los efectos políticos actuales.

Política de innovación regional Modelos dinámicos Flujos de conocimiento

JEL classifications: O38, R11, R58

\section{INTRODUCTION AND AIMS}

A considerable degree of diversity in regional innovation performances is empirically detected in studies such as the European Regional Innovation Scoreboard exercise (Hollanders et al., 2009), which also showed that regions have different strengths and weaknesses. Moreover, the innovation scores of the European regions examined in the exercise appear to be quite stable compared with the previous exercises of 2004 and 2006, signalling that regions are more and less innovative in nature. For instance, USAI (2011) showed that inventive performance at the Organisation for Economic Co-operation and Development (OECD) level is concentrated in regions characterized by human capital and research and development (R\&D) expenditure. Indeed, regions appear in many cases to belong to different regional innovation models (CAPELlo and LenZi, 2015)

Empirically, it appears that the same innovationrelated factors are not identically relevant for all regions. Moreover, the innovation-growth relationship is not equally important for all regions. STERLACCHINI (2008) showed that while highly educated people were beneficial to the gross domestic product (GDP) growth of all European regions, R\&D expenditure was beneficial only for those above a certain threshold of GDP per capita. Additionally, the relationship between regional human capital and $\mathrm{R} \& \mathrm{D}$ and regional growth was evident for northern European countries but not for southern ones.

These theoretical findings are not easily reconciled with policy efforts, which are too often similar rather than differentiated between regions with different types of innovation systems (OECD, 2011). For instance, after the failure to achieve the Lisbon Strategy objectives, the new Europe 2020 strategy targets involves 'smart, sustainable, inclusive growth' and a target of $3 \%$ for the share of R\&D expenditure on GDP. Within this strategy the flagship initiative 'Innovation Union' includes, among its objectives, 'Spreading the benefits of innovation across the Union', and states: 'The Innovation Union must involve all regions. [...] Europe must avoid an 'innovation divide' between the strongest innovating regions and the others' (EUROPEAN COMMISSION, 2010).

To implement this objective with a call for one-sizefits-all innovation policies would lead to lower performance than could be achieved with smarter, place-based, policies (BARCA et al., 2012). This is particularly the case because the literature shows that innovation needs prerequisites (Rodríguez-Pose, 1999, 2001; CresCENZI and RODRÍGuez-Pose, 2011); even where regions are apparently similar, new knowledge can only be built upon previously existing knowledge, so that innovation is a cumulative process localized at sectoral and territorial level (FAGERBERG, 2005).

This paper builds a tool to measure ex-ante the impact of various types of innovation policies at regional level on growth and income through their influence on intra- and inter-regional knowledge flows. A model is developed and calibrated on a generic European region in order to show the impact of different policies. The model, if calibrated on individual regions through extensive fieldwork, could also be used as a normative tool to assess ex-ante policies at the individual regional level. The paper will also show that different types of innovation policies have different impacts in time and depend on regional contexts, therefore supporting the need of region-specific policies.

The model presented in this paper is built using a dynamic evolutionary simulation approach first developed by FRATESI (2010), based on a system dynamics methodology. In this approach, 'soft' modelling is adopted where it is not possible to solve the model analytically and the possibility of optimizing the behaviour of agents is limited. However, in this approach, the simplifications required by traditional 'hard' modelling techniques are not needed, and it is possible to take into consideration concepts that are normally expressed in word terms, for example by heterodox theories. Heterodox deductions and theories can also be logically tested if formalized in this way, and when dealing with innovation at territorial level the advantages clearly overcome the limitations. In particular, it is helpful to represent loops and feedbacks that are theoretically evident but hard to represent with traditional techniques.

The simulation model built in this paper can represent the flows of knowledge within regions. The model is unique but designed to represent different regional innovation models - some flows can be switched off either exogenously or because some specific typologies of agents (such as researchers, inventors, educated people, creative ones, innovative firms) are too scarce in the region at the start of the simulation. Hence, it is possible to simulate the different 
mechanisms by which different types of regions can innovate and produce goods, and thus develop an understanding of their different roles in a knowledge economy.

The paper is organized as follows. The second section outlines the main traits of the methodology. The third section describes the model and the theory behind it. The fourth section shows how the model is calibrated to an 'average' European Union (EU) NUTS-2 region, using real data as far as possible. The fifth section presents some example simulations. The sixth section concludes and also presents the scope for further research.

\section{THEORY AND METHODOLOGY}

Most of the literature on innovation at the regional level is not formalized and follows three approaches:

- Conceptual studies, which are based on the capability of the researcher to identify, describe and, in some cases, classify the relevant concepts.

- Case studies, which are very interesting in the sense that they can go much deeper into the analysis of specific regional innovation systems, but are at the same time obviously limited in their ability to abstract the general from the particular.

- Empirical-econometric papers, in which hypotheses are made and tested through the use of statistical proxies for the concepts, quite often testing reduced forms.

This paper follows a different approach: it is formalized but uses a 'soft' modelling approach, developed below.

Five scales are needed to define the approach used in this paper. The first three come from Boschma and FRENKEN (2006), who identify three dichotomies that are needed to classify a research approach in economic geography: (1) the use of mathematical formalization; (2) the assumption of the rationality of agents, which can involve full rationality or bounded rationality; and (3) the dynamic characteristics of the description, which can be static, based on comparative equilibria or, at the other end of the spectrum, fully dynamic, i.e., also investigating disequilibria trajectories.

The fourth dimension comes from CAPELLO (2007), according to which the conceptualization of space can be abstract and stylized (suitable for formalizations), or relational, when space is conceived as the support where many different sets of relations between economic agents can exist (in this latter case formalizing is more difficult). Finally, the fifth dimension concerns the scale of the arguments, which can range from macro to micro, with a so-called meso-approach between the two in which neither aggregates nor individuals are considered, but the focus is on institutions, groups of agents and their interactions (appropriate for studying, for example, routines, sectors and common practices).

With these dimensions in mind, the present study will use an approach based on evolutionary economic geography as defined by BOSCHMA and FRENKEN (2006): it is formalized, has bounded rationality and is essentially dynamic. The conceptualization of space aims at being relational; however, it is not possible to achieve this because of the need for formalization and the scale of arguments will therefore be essentially meso-economic.

A dynamic modelling methodology features the precious characteristic of interrelation: each economic sector can be linked with all other relevant ones and the representation of the production and diffusion of knowledge may include all the agents considered to be involved in these processes at the territorial level.

Many ways of dealing with simulation models are outlined in the literature, although more often in engineering or environmental studies than economics. Here, the chosen approach is a system dynamics one. The choice of system dynamics above other simulative approaches is due to the ease of achieving the aims of this work, especially because the approach allows two different phases to be separated out in the modelling process (Wolstenholme, 1990):

- The design of the structure of the model according to the theoretical relationships which are considered most important by the modeller.

- The formalization of the equations according to the relationships that are specified in the first phase.

Separating out these two phases is very useful when dealing with very complex systems such as regional innovation systems: this is why, for example, the description of the relationships and the theory behind them is given in the third section, while the calibration and simulations are in the fourth and fifth sections of this paper.

Moreover, the explicit inclusion of feedbacks are characteristic of system dynamics, which is helpful when modelling regional systems: increases of production and employment in the region, for example, will lead to increased wages and production costs, which are detrimental to further increases of production and employment. Neglecting these feedbacks would lead to a model in which improving a node of the model means everything improves by definition, which is hardly compatible with reality.

Harder modelling techniques, such as agent-based models or computable general equilibrium models, could also be used for policy assessment. In comparison with these, the system dynamics approach is not optimizing because it is not based on individual agents taking rational choices. The advantage, however, is the fact that the time dynamics of flows can be represented and modelled clearly and consistently, and the targets and direct and indirect impacts of policies 
represented more effectively, so that the policy levers are explicit.

System dynamics, like other aggregate approaches, is exposed to the Lucas critique, whereby the behaviour of agents can be influenced by policies; at the same time, there is ample consensus in the literature that regional agents are not fully rational and optimizing, and since policies tested with a model like the one used in this paper have to be realistic, it is acceptable to think that realistic policies, being constrained in their size, do not significantly affect the behaviour of individual agents. It would be different if a policy were to use huge resources, so that it could radically change the regional economy; in that case, with a different local system, the behaviour of agents would certainly be affected. Unfortunately, however, the resources available for policies are never very large; for example, the EU budget hovers around $1 \%$ of EU GDP, and only about onethird is used for Cohesion Policy.

In the system dynamics approach the modelling process starts with the identification of stock variables, those persistent in time. These variables give inertia to the whole system because they maintain their value after each run of the simulation, unless affected by inflows or outflows (e.g., the population is affected by births and deaths, or patents are affected by new patent applications and by the expiration of existing ones). A model basically becomes a system of difference equations, where stocks evolve in time as follows:

$$
\begin{aligned}
\text { stock }_{t+1} & =\text { stock }_{t}+\text { flow }_{t}, \\
\text { where flow } & =\beta \text { stock }_{t}+\gamma_{t}
\end{aligned}
$$

In Fig. 2, stocks are represented with boxes and flows with thick arrows with a sort of hydraulic tap. The simpler relations, in which the value of a variable at time $t$ is used to calculate the value of another variable at the same time $t$, are represented by thinner arrows. It is also possible to introduce variables that are neither time persistent nor directly affecting the stocks, if the modeller thinks they are important enough to be autonomous in the model rather than just values within the various equations.

The system dynamics methodology makes it compulsory to distinguish $e x$-ante which variables are persistent (stocks), which variables affect them (flows) and which variables are determined at each simulation run. This forces the modeller to be theoretically consistent; in the empirical literature, however, searching for regressors is often less rigorous, and different papers may use endowment and variation. There must therefore not be confusion between patenting versus stock of patents, R\&D versus knowledge, infrastructure versus infrastructure investment, educated workforce versus attraction of graduates, and so on.

One important point to consider when analysing a dynamic system is the distinction between processes that change at different speeds. As first emphasized by the synergetics literature (HAKEN, 1983, 1985), and applied with success in models of transport, urban and regional evolution (ANDERSSON, 1986; BATTEN and JOHANSSON, 1987; JOHANSSON, 1993; JOHANSSON et al., 2001), not all changes take place at the same pace and some slow-moving processes can act as an arena in which faster moving processes play their game. At the same time, perturbations in the fastmoving processes can lead to catastrophic changes in the slow-moving arena, if they are close to the bifurcation points. BARKLEY ROSSER (2011) distinguishes between three groups of changing processes in urban evolution: slow (e.g., industrial, residential and transport construction), medium (e.g., economic, demographic and technological change) and fast (e.g., labour, residential and daily mobility).

The model developed in the following sections is devoted to simulate policies to analyse short-tomedium-term policies, which act on regional competitiveness through an impact on the knowledge flows. Slow changing ('arena') processes, such as institutions, are normally inserted through parameters, i.e., are not directly modelled as endogenously changing, since their evolving time would be on a different scale with respect to the one of regional policy, but can be modified to simulate different regional milieus and hence the same policy in different regional contexts/arenas. Medium-speed processes are modelled through the persistence allowed by the stock and flow structure, so that, for example, an increase in the speed of patenting only slowly changes the stock of existing patenting, while fast processes are levers of the model which can be changed immediately.

As for all modelling methodologies, it is easy to succumb to the temptation to add complexity by including relationships that are realistic but not really necessary, making it harder to understand what stands behind the results obtained with the model. This is a common issue in science, and is described in Occam's razor, or its modern version, the 'verisimilitude trap' (Gilbert and Doran, 1994).

The second step of the modelling process is to enter the actual equations, which is possible only according to the diagram previously designed, i.e., using the variables indicated by the arrows, with freedom to choose the best mathematical form for each equation.

In the modelling process, since time dynamics are very important, great attention has to be paid to the fact that different types of resources have different degrees of mobility between regions. For instance, consistent with the literature, different economic agents and people have to be assumed to be differently mobile (Fratesi, 2014b). Moreover, it is important to be aware of the fact that different processes work at different speeds. The model developed in this paper, for example, has a complex cohort-demographic mechanism for ageing and training, which takes into account 
the slow evolution of the processes concerning people; the policy simulations that are implemented also take account of these points, as it would be absurd to implement in one period a policy with an infrastructure increment of $20 \%$. On the contrary, it is possible suddenly to increase the public research budget by $20 \%$, even if it takes time as money goes into research, then patents and then products.

This dynamic methodology was introduced by FRATESI (2010), where its advantages are critically discussed with the help of a theory-based model. The present study is an ambitious further step insofar as it aims to draw policy conclusions for actual regions rather than theoretical ones. For this reason, a model is built, consistent with the theory, in which actual regional values can be entered rather than theoretical ones.

In this paper the model is built at the regional level, and calibrated on the actual values of an average EU NUTS-2 region. Another possibility would have been to calibrate it on a functional urban region. The latter option would have brought the advantage of being more consistent with the theory, having a self-contained labour market; NUTS-2 regions often contain more than one labour market, and in some cases share some local labour markets with neighbouring regions. The choice of NUTS-2, however, is justified by the fact that the model is to be used as a policy tool, and hence needs to be calibrated on a unit with policy relevance. For some European countries (e.g., Italy and Spain), NUTS-2 regions coincide with administrative units, while for other countries, where administrative units are different (e.g., Germany, where the landers are NUTS-1) NUTS-2 still has meaning as the unit of measurement in which eligibility for EU Structural Funds is calculated. Currently (and perhaps unfortunately), functional urban areas that exist in economic terms are very rarely endowed with administrative powers.

\section{THE MODEL}

\section{General features}

The model developed in this paper builds on a number of stylized facts taken from the very wide literature on innovation at regional level. In particular, inspiration is taken from studies that view innovation as an evolutionary process (NELSON and WINTER, 1982; LUNDVALL, 1992; Nelson, 1993; Edquist, 1997), studies on clusters and regional innovation systems (ASHEIM et al., 2006; BRACZYK et al., 1998; Lundvall, 1992), studies on the recently labelled 'Evolutionary Economic Geography' (Boschma and LAmbooy, 1999; Boschma and Frenken, 2006; Kogler, 2015), studies on knowledge spillover and other mechanisms for the interregional transfer of knowledge (Audretsch and Feldman, 1996, 2004; Breschi and Lissoni, 2001, 2009), and on the role of socioeconomic factors as a filter for innovation at regional level (CRESCENZI and RODRÍGUEZ-POSE, 2011).

The model is also clearly inspired by cumulative causation models (MYRDAL, 1957; KALDOR, 1970; DiXON and THIRLWALL, 1975) and adopts a territorial capital perspective in which a region is studied in its material and immaterial, private and public assets (CAMAgNi, 2009).

The model built for this paper represents the basic structure of a regional knowledge economy, and can be expanded to allow for further complexity or different aspects where necessary, such as for application to a specific region, or to unbundle some sectors from the others for the study of sectoral-specific policies.

As shown in Fig. 1, the model is built on two main elements:

- An internal knowledge-circulation dimension.

- An internal-external knowledge dimension.

The internal knowledge-circulation dimension is built on three main stocks: knowledge, patents and highlevel products (lower-level standardized products are less important in the knowledge economy so they are modelled in lesser detail). Knowledge circulation tends to follow a 'refined linear model' (BALCONI et al., 2010) in which traditional mechanisms are present but interactions - more recently introduced in the literature - are also taken into account.

The internal-external dimension is reflected by the activation of flows between the region (whose boundary is represented by the dotted circle in Fig. 1) and the external world. There are in fact a number of flows linking the region and the rest of the world, essentially concerning four groups of assets: knowledge, people,

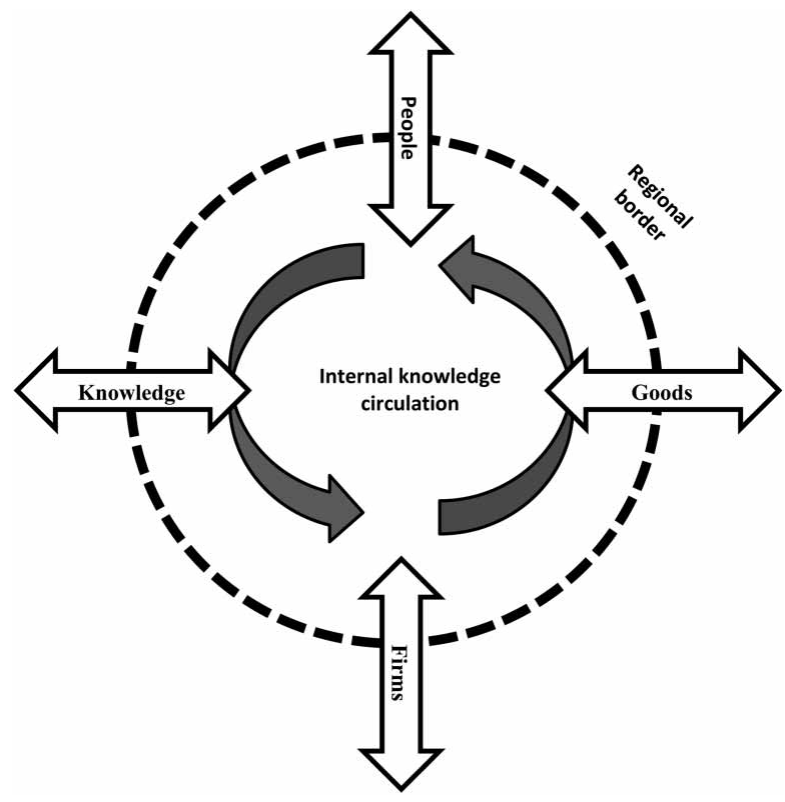

Fig. 1. Flows in the model 
goods and firms. The three material flows can also carry knowledge, which is transferred with people, firms and goods. Especially relevant are the flows of people and firms, since these bring with them the possibility of the transfer of knowledge, consistent with the most recent literature on spillover, which has found the mechanisms underlying spillover in the mobility of personnel (e.g., Moen, 2005). However, trade also brings possibilities for learning, since people and firms can learn from imported goods or the procedures of the firms exporting them.

\section{From knowledge flows to patents to products}

The model includes explicit and tacit knowledge. The first is modelled through three interacting stocks (see the lower left of Fig. 2; and see Fig. A1 in the supplemental data online):

- Internal knowledge, which is exclusive to the region and is available elsewhere. This is increased by basic research, which is performed by basic researchers but assumed to be facilitated by the presence of applied researchers in the region. ${ }^{1}$ This is consistent with studies that see a role for business-university interactions in the construction of knowledge (LEYDESDORFF and ETKOWITZ, 1998); moreover, the public research budget is assumed to be relevant to the ability of basic researchers to create new knowledge, as research and laboratories need funding.

- Shared knowledge, which includes explicit knowledge not exclusive to the region but shared with other regions. Shared knowledge is incremented by outward spillover from the region, which makes knowledge that was created internally available also externally, and inward spillover (described below). The magnitude of outward spillover is dependent on the stock of internal knowledge, but also on the outward flows of three types of agents able to carry knowledge - basic researchers, applied researchers and entrepreneurs/firms - as well as openness to trade. Shared knowledge is usually relatively old since it has been invented somewhere and afterwards 'copied' elsewhere, so the stock of shared knowledge also has a dissipative mechanism of obsolescence.

- External knowledge, which is not known in the region but known elsewhere. Its growth is incremented exogenously through technological progress, which is assumed for simplicity to be independent of the modelled region, since only in a very few cases worldwide does the amount of new knowledge produced in a region have a relevant impact worldwide. Inward spillovers are represented by elements of external knowledge becoming known within the region, i.e., entering the stock of the shared knowledge, and depend on the inflows of economic agents such as basic researchers, applied researchers and firms/entrepreneurs; private research budgets are also assumed to be relevant, since they help reverse engineering, patent acquisition and other processes which support the acquisition of external knowledge. Finally, the more a region is open to trade, the more likely are inward spillovers.

With the three stocks of knowledge a synthetic indicator is built to measure the ability of the region to invent new things, which depends not only on how much knowledge the region possesses but also on its share of the knowledge possessed worldwide. The indicator is called the 'knowledge gap' and ranges between 1 (where all world knowledge is known in the region) and infinity (where the region knows nothing), and is defined as follows:

$$
\begin{aligned}
& \text { knowledge gap }=\frac{\text { total knowledge }}{\text { regional knowledge }} \\
& =\frac{\text { external knowledge }+ \text { internal knowledge }+ \text { shared knowledge }}{\text { internal knowledge }+ \text { shared knowledge }}
\end{aligned}
$$

Still following a refined linear model, the knowledge gap is the basis of the regional ability to produce new patents, which in the model are also a proxy of market-usable regional knowledge. The model therefore applies a process in which knowledge is used to produce patents and patents are used to invent and introduce products (see the upper part of Fig. 2; and see Fig. A2 in the supplemental data online) involving two main groups of economic agents: applied researchers and entrepreneurs.

Creating new patents from regional knowledge requires applied researchers as well as the intervention of research funds (which in the simplification of the model are assumed to be coming exclusively from the private sector), and the presence of the right institutions, consistent with theories of the so-called 'social filter' (Rodríguez-Pose, 1999). It is a known fact that some regions possess institutions that facilitate knowledge flows within regions and better allow knowledge to translate into new products, while other regions have institutions that are innovation harmful (Crescenzi and Rodríguez-Pose, 2011). These are the institutions that are most relevant in the context of this paper. Since patents expire and their usefulness decreases as technology progresses and new techniques replace older ones, they are modelled to have a mechanism of obsolescence.

Patents do not transform automatically into products that can be sold in markets, but need a mechanism involving uncertainty (which can be modelled stochastically ${ }^{2}$ ) and the intervention of specific agents, i.e., entrepreneurs. The action of entrepreneurs is made easier by the possibility of obtaining financial capital to fund their entrepreneurial initiatives. For traditional firms this means low real interest rates and, for the 


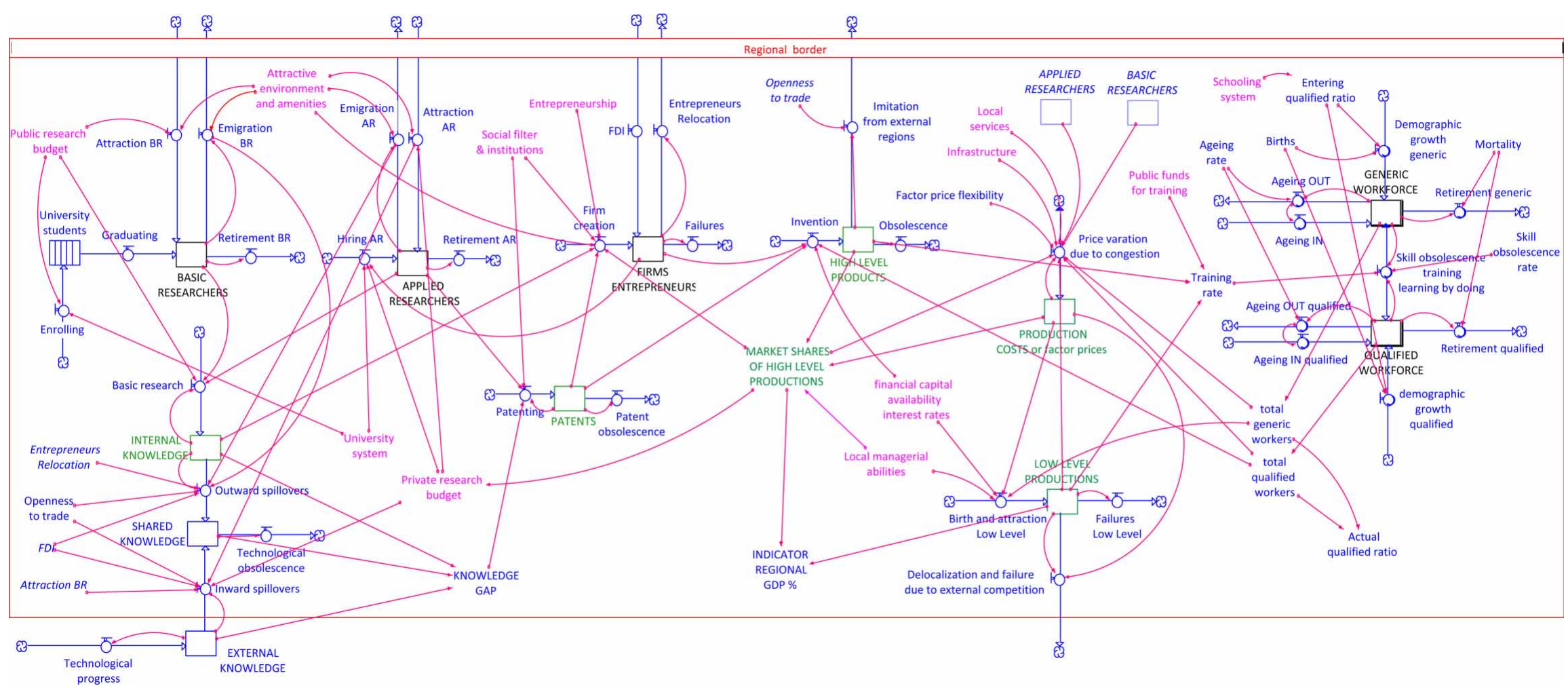

Fig. 2. The full diagram of the model (enlargements are in Appendix $A$ in the supplemental data online) 
most innovative entrepreneurial activities, the presence of venture capital.

'High-level products' are modelled as a stock since, even with shortening product life cycles, every product stays in the market for a while before being replaced by others. Since products are subject to obsolescence and external competition, their stock needs to be continuously replenished. If the region is more open to trade, it is easier for competitors to imitate products.

All processes of knowledge creation should be modelled at least stochastically, since all innovation involves uncertainty (NeLson and Rosenberg, 1998). However, if the purpose is to use this typology of models for ex-ante policy assessment, the 'expected outcome' of policies is the most relevant variable, and the use of confidence intervals is rarely seen in this kind of exercise. For this reason, the model is calibrated deterministically and its results, presented below, are deterministic, although there is a fully functioning version of the model in which stochastic results of the process are included.

The economic agents involved in the knowledge and economic processes

As stated above, three sets of agents are explicitly involved in the knowledge economy: basic researchers, applied researchers and entrepreneurs (Fig. 2). All three are mobile between regions and can be attracted to or relocate/emigrate out of a region in search of better conditions. An attractive environment and the presence of amenities is a determinant of the inflows of all three. While all three sets of agents are mobile between regions, they are not assumed to be equally mobile, as their migration parameters are different - for example, the entrepreneurship literature shows that entrepreneurs mainly start firms in the region where they live - and they need networks to be effective in their activities (FIsCHER and NiJKAMP, 2009).

Basic and applied researchers are also subject to 'retirement' processes in order to model the fact that these agents also have a working lifespan after which they either retire or lose their creative and innovative impetus. For entrepreneurs, age is not as important as the ability to be creative and innovative, as shown by the highly non-uniform distribution of the ages of entrepreneurs owning start-ups. The regional ability to educate and hire basic and applied researchers is affected by the level of schools and universities, their educator role still being highly relevant (VARGA, 2009), while the public research budget is also a factor in attracting basic researchers in search of funds.

As already mentioned, the mobility of specific agents is a clear channel of inbound and outbound knowledge flows, and, following recent empirical literature (BRESCHI and LisSONI, 2009), the model developed here accounts for the interregional mobility of knowledge through the mobility of specific groups of people. For example, attracting basic researchers facilitates the expansion of the stock of regional knowledge (Fig. 2). The model could in future be extended to become a multi-regional model by linking regions through flows.

The modelling of the tacit knowledge mechanisms (first introduced in the literature by POLANYi, 1969; and RosenberG, 1982) and learning by doing are captured in the model by the capabilities of workers. These can represent either a 'generic workforce', only possessing generic abilities, or a 'qualified workforce', with specific abilities that cannot be learnt at school (see the right of Fig. 2; see also Fig. A3 in the supplemental data online). The two stocks of workers start therefore from the same source (i.e., demographic growth), but the quality of schooling decides the share of new workers who are generic and need training and/or learning by doing to become qualified - probably the larger part.

Both generic and qualified workers have a full demographic mechanism of ageing, with people in 40 separate cohorts (assuming 40 years as the maximum working life of people) and a retirement mechanism that starts acting with increasing rates with the increase of age. In Fig. 2 this is represented, synthetically, with overlapped squares, meaning that these are not simple stocks but matrixes of stocks (in this case 40 stocks, one per age group).

More relevant to the knowledge economy, people in the model not only age in each period but also can acquire skills and expertise, or become unskilled if their expertise becomes obsolete - skills are also subject to obsolescence and need to be renewed and replaced, and this normally happens at rates increasing with age. This is modelled with a bi-directional mechanism of obsolescence and training/learning by doing, linking the two stocks of qualified and generic workforce, in which various factors influence the percentage of people of each age group that gains skills or becomes unskilled. These factors are assumed to be the public funds for training and the presence in the region of especially high-level - production.

This complex demographic mechanism is important because if people are trained when they are close to retirement, they will be able to use their increased expertise only until they exit the labour market. In this way, the cohort-demographic mechanism can also consider the presence in the region of a younger or an older population and labour force.

\section{Congestion, factor costs and regional wealth}

With respect to congestion, factor costs and regional wealth, a dynamic system approach proves useful. In fact, all the flows represented in the previous sections can trigger positive loops for the region, but it is impossible in the real world for a region to become too big in 
economic terms with respect to its population and size, and it is also difficult to become drastically richer than other regions, owing to the pressure on factor prices and the insurgence of congestion diseconomies after a certain threshold. Without compensating mechanisms, the cumulativeness of knowledge, with ARTHUR's (1994) increasing returns to scale, would lead to indefinite growth inside the region as a consequence of increasing returns in the innovation process. The dynamic methodology allows one to model the negative feedbacks from success to increased costs, so that the attractiveness of the region for further economic activities is counterbalanced by larger production costs.

The model includes a 'congestion' mechanism (see the centre of Fig. 2; see also Fig. A4 in the supplemental data online), where congestion is due to the presence of people and firms in the region, meaning slightly greater weighting for those people and firms which are likely to be richer and hence consume more resources. Congestion is the determinant of local 'production costs', where factor prices increase with the pressure on them. Production costs are represented with a stock for a technical reason: this allows a delay between the increase or decrease of congestion and the increase or decrease of factor prices. Prices are sticky, for example, because wages are set for the length of contracts, and hence it would be unrealistic to assume that they vary instantaneously. Prices hence adjust to congestion as follows:

$$
\begin{aligned}
\text { prices }_{t+1} & =\text { prices }_{t}+\operatorname{adj} *\left(\text { Prices with congestion }_{t}\right. \\
& \left.- \text { prices }_{t}\right)
\end{aligned}
$$

where adj (between 0 and 1) is the speed of adjustment and actual prices adjust to prices with congestion in time. By varying the value of adj, it is possible to model different regional situations in which prices are more or less flexible. This price stickiness is important in the simulations because it is an important determinant of the speed of feedbacks in the economy, and hence of the time delay of policies.

Production costs and the number of high-level products developed by the regional knowledge mechanisms are the two main determinants of the regional market shares of high-level products. Firms will decide to produce high-level goods and services in the region unless high production costs convince them that it is convenient to shift production elsewhere. Local managerial abilities can influence these location choices. The presence of firms producing high-level products in the region positively influences the amount of private resources devoted to regional innovation, thus feeding the knowledge production mechanisms.

No region produces only high-level products; traditional low-level goods and services are also produced. Being marginal to the knowledge economy, these are modelled in less detail (see the lower part of Fig. 2); as they are non-innovative, the competitiveness factors are also different and clearly more closely linked to traditional location factors such as production costs, congestion, the presence of a labour force, and the availability of cheap financial capital for investments and of local managerial competences.

Both high- and low-level production (though the former does so to a larger extent) contribute to the level of income per capita in a region - which is the final indicator of the model, although it cannot capture the complexity of economic development. It should be clear that the model is thus not a generative growth model but a 'competitive' one, in RICHARDSON's (1978) terminology. The absolute growth rate is not determined in the region, and nor is growth at the world scale; however, the region can place itself lower or higher in the ranking of regions depending on how well knowledge-creation mechanisms work.

As a model whose aim is to simulate the impact of policies, this is not a shortcoming, since a policymaker needs to evaluate a policy against a counterfactual of 'no policy', or to test one policy against another. The absolute growth rate of an economy does not depend on the region itself, but the region can be more or less sensitive to the movements of the national and global economy. For example, almost all regions lost jobs in the current economic crisis, but those with better knowledge mechanisms and better policies have lost the fewest.

\section{CALIBRATION OF THE MODEL}

Three options are possible to calibrate the model before using it for policy simulations. ${ }^{3}$ One option is to calibrate it on theoretical values, which works better if all values are standardized, because in this way the values are immediately comparable. This is the option taken in the earliest attempts with this methodology (Fratesi, 2010). This method is relatively easy and can lead to important theoretical results, but these will also be most abstract and difficult to interpret from a policy point of view.

Another option is to calibrate the model on the actual values of a specific region. However, this would be very hard to implement since the exact values of the parameters in a region, especially sensitivity parameters, are impossible to obtain without specific and intensive fieldwork. In addition to the practical difficulties, calibration with data on one region would only produce results valid for that specific region, which would be difficult to generalize.

In this paper a third, intermediate, option is used, which is better suited to analyse general policy issues and to show the importance of place-based policies. The model is calibrated, whenever the data allow, on a generic European region, using data mainly from European statistical sources, such as the Regional Innovation Scoreboard Exercise (HOLlanders et al., 
2009). ${ }^{4}$ The values for this generic region, as mentioned above, are assumed to be the average of European NUTS-2 ones. The calibration on a generic region will form the benchmark on which other types of regions can be represented, starting from the generic region and changing the values of the relevant nodes (stocks and parameters, especially those determining the arena, i.e., the local economic milieu) when needed, in order to analyse the impact of policies in different types of region.

The choice of representing regional GDP with a per cent of the EU average, rather than an absolute value, comes from the focus of the model on supply-side aspects. While demand-side aspects are indeed important, this method allows one to neglect macroeconomic cycle issues, such as the economic crisis, which affect all regions, though in different ways. Region-specific demand issues, for example due to sectoral specialization, can be included in the model at a later stage, when policy-makers need to see the impact of sectorspecific policies.

Those parameters not available from statistical data can be estimated by (expensive) fieldwork once the model is applied to a specific region. In this pilot exercise, they are set to plausible values, in particular assuming that the elasticity of one variable to another, as one among several influences, is smaller than 1 , and that the elasticity with respect to more important variables is larger than in relation to less important variables.

The model is non-linear, but is calibrated in a stable equilibrium, and all simulations take place in the region of the same equilibrium, which is justified by the fact that policies are normally incremental.

Thanks in particular to the time delays of the model (due to price rigidity, the time needed to build stocks of items such as patents and the inertia in the demographic mechanisms), it will be possible to observe the dynamics of policies, since any policy needs time delays:

- to impact on the direct target; and

- to affect the whole regional economy.

Being systemic, this approach can also take account of indirect and recursive, second- and third-order effects, as already mentioned. In this way it is also possible to observe which policies are more effective in different types of region and which can produce more immediate impacts.

\section{POLICY SIMULATIONS AND RESULTS}

The aim of this section is to present the potential of the instrument with some illustrative policy simulations and some important issues related to the policies, in particular concerning the different impacts of conjunctural versus structural policies, with the former defined as those that temporarily alter the status of the regional system without altering its long-term equilibrium, while the latter are defined as those policies aimed at altering this long-term equilibrium (i.e., for what possible, the 'arena'). Attention is also paid, as favoured by a dynamic approach, to the time impacts of policies, which are generally inadequately considered by policy-makers, probably because of the scarcity of instruments to carry out relevant analysis.

This type of model can produce an almost unlimited number of policy simulations so a few examples are selected here in order to show the general conclusions on the utility of this type of model. In particular they demonstrate the utility of analysing a policy's quantitative impact before its implementation, and the time delay of this impact at the same time. It is less meaningful at this stage to compare two policies based on the absolute size of their impact, because it is easy to achieve a higher impact by introducing a larger change in the policy variable. This would only be relevant at a later stage in which a model such as this could be applied to a real region rather than a standardized one.

In addition to the above, other simulations show the different impact of policies in different contexts. Applying policies to different regional contexts can also obtain very differentiated results, also from an aggregate point of view (FRATESI, 2008), an outcome recognized by supporters of place-based policies (BARCA et al., 2012) but generally not modelled due to practical difficulties.

One key question for any policy simulation is the cost of policies, since public finances are increasingly being constrained, especially as a result of the economic crisis and, in Europe, the Stability and Growth Pact. However, regions normally have no or very limited taxation power, and most of their resources come from higher bodies such as the nation-state or the EU. For this reason, rather than including a mechanism of local taxation (which would be possible, making the model more complex and less realistic), this model instead concentrates on the impact of policies, assuming that a region has a budget to use. This is, for example, how the Structural Funds work in Europe: the amount is decided at the beginning of the seven-year programming period and the money is then used according to programming documents.

The first simulation is the comparison of two conjunctural policies to show not only that two policies can have impacts of different magnitude but also that even when the absolute magnitude of the impact is the same they may have different time impacts, which makes it impossible to compare them by just looking at a single indicator without observing their time effects (Fig. 3(a)).

In this case there are two different positive shocks inserted in the model, one that temporarily decreases the production costs (such as temporary de-taxation of work) and one that temporarily increases basic research in the region for a limited amount of time (such as temporary research incentives). Since basic research needs 
time before patents are developed and products enter the market, the first policy has a more immediate

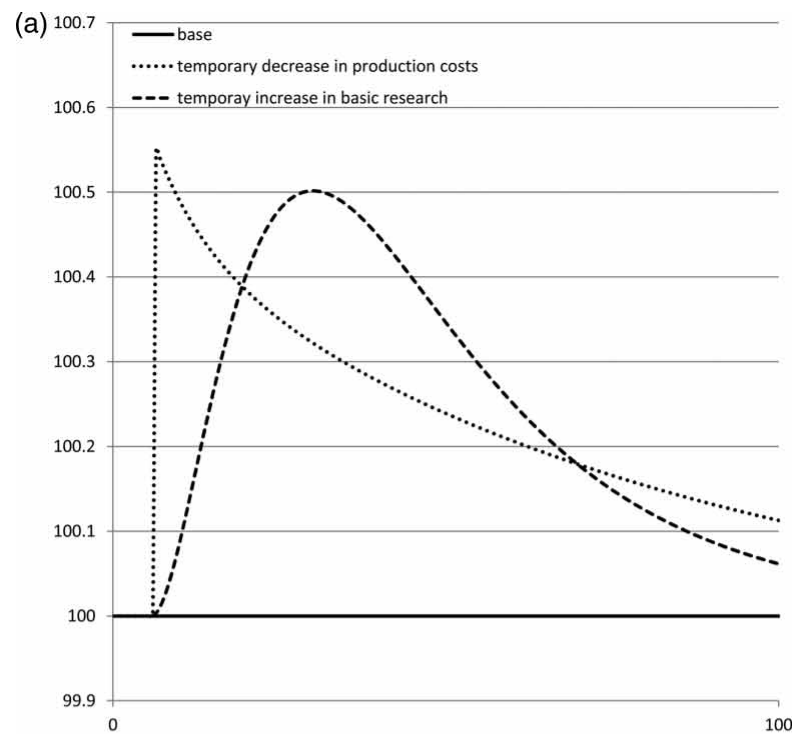

(b)

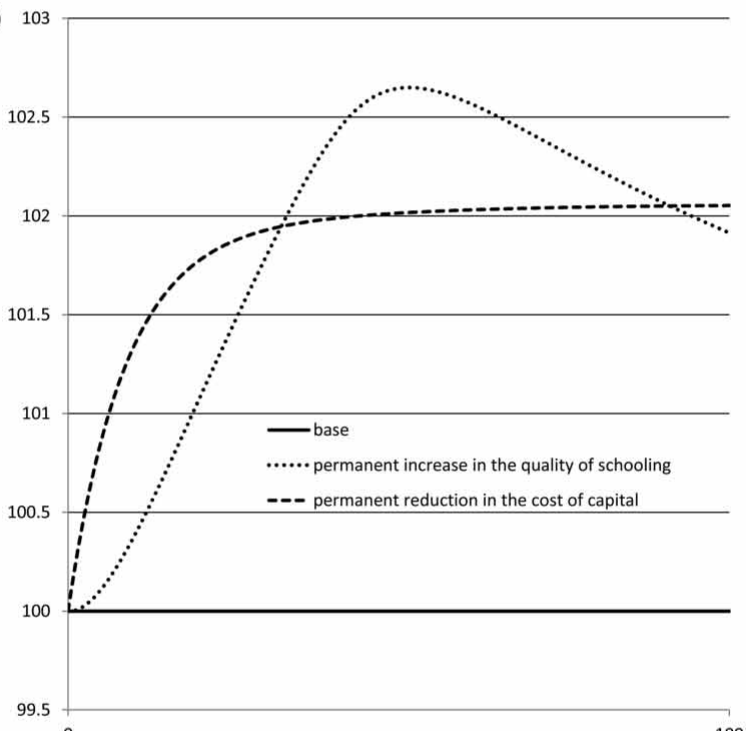

(c) 102.5

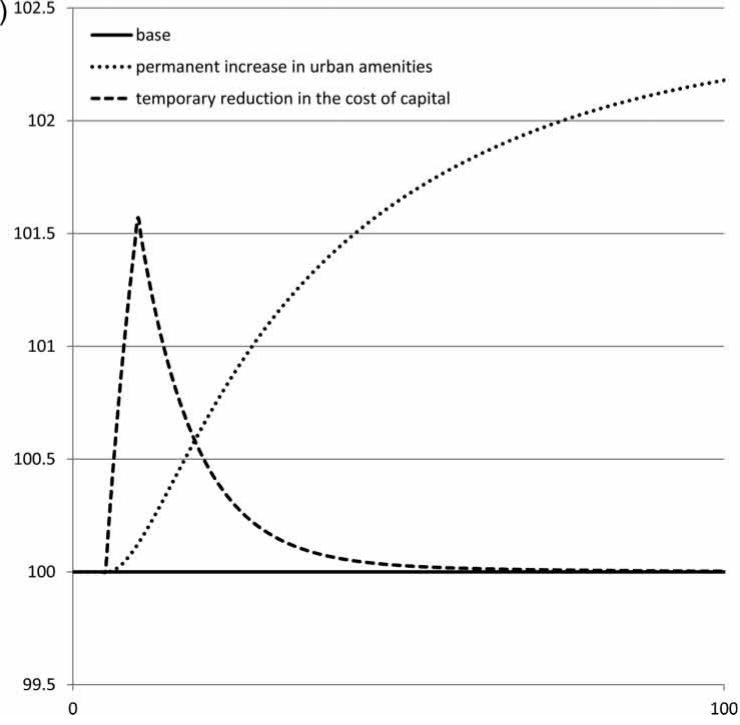

Fig. 3. Examples of policy simulations with the model impact, which, however, fades with the end of the incentive.

The second simulation concerns the comparison of two structural policies, which produce long-term changes, although again with different time effects (Fig. 3(b)). In particular, in this case the two policies are a permanent reduction of the cost of capital in the region (e.g., with a better implementation of the rule of law) compared with a policy that makes educational institutions produce qualified workers at a higher rate. The latter needs time to affect the labour force, starting from the first cohort of workers, but the former has a more immediate impact. Moreover, due to increased wages, the latter also has an 'overshooting' effect.

The third simulation compares a structural and a conjunctural policy (Fig. 3(c)). The structural policy is in this case a permanent increase in the level of urban amenities, which, in time, would favour the attraction of creative and knowledgeable people, and therefore also inward spillovers and regional innovation. The conjunctural policy is a temporary reduction of the cost of capital (e.g., driven by de-taxing capital invested in a

(a)

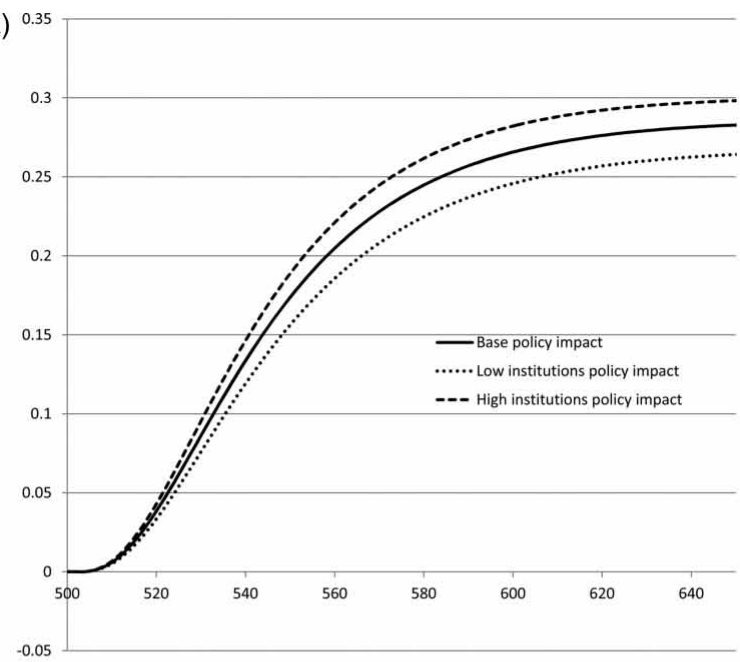

(b)

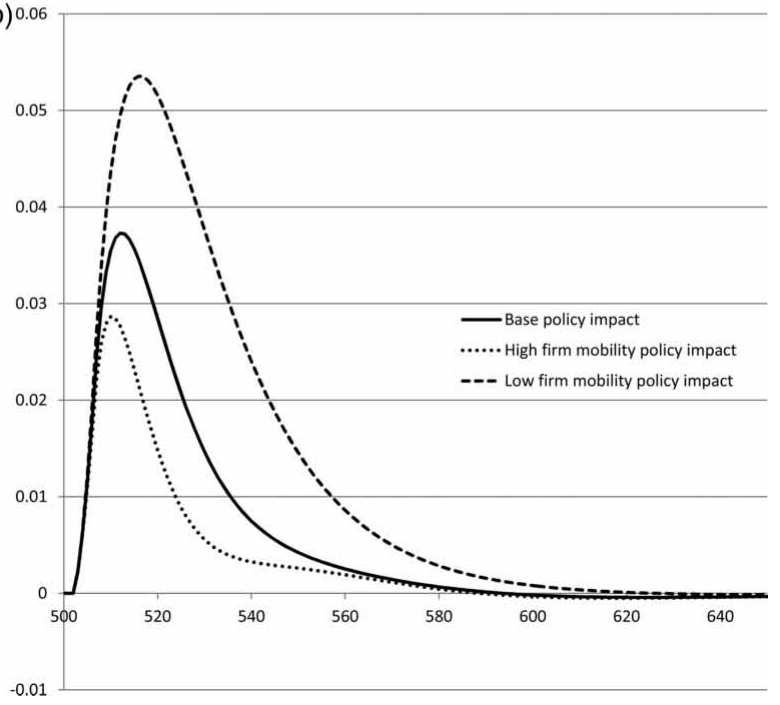

Fig. 4. Impact of the same policy in different regional situations 
region). Although the structural policy is in this case to be preferred in the long run, it is clear that it cannot pull a region forward in the short run, and for this reason the best option to ensure an immediate and lasting impact would be a mix of the two policies.

Comparing policies in the same regional situation is just one possibility allowed by the model. In fact, regional scholars are increasingly in favour of placebased policies, being convinced that policies need to be targeted at the specific regions in which they are deployed in order to be effective (BARCA et al., 2012). For this reason, Fig. 4 models the impact of the same policy in different regions.

The first experiment deals with the impact of a $10 \%$ increase of public research budget (say, new funds for research projects) on the indicator 'GDP\%' (Fig. 4(a)). This is a policy that needs a long time before being effective, since it must move from knowledge to patents and then products. What is really interesting to observe, however, is its impact in different contexts. The base simulation is the policy applied to the standard calibration region, the one at $100 \%$ of the EU average.

The other two simulations apply to a region with a high level of institutions, which is innovation prone, and to a region with a low level of institutions, which is less innovation prone. In the model, institutions act as a social filter, which allow basic knowledge to be more easily applied and become patents, and prospective entrepreneurs to start-up businesses more easily using new ideas and new patents. In the first case, ceteris paribus, the regional equilibrium with no policy is higher than $100 \%$, while in the second case the equilibrium is lower.

Given this paper's interested in the policy impact, the differential made by the policy is depicted in Fig. 4(a), rather than the absolute value of the indicator. As can be easily observed, the same increase of the public research budget produces a larger impact in a region with more innovation- and entrepreneurship-friendly institutions, while the impact of the policy is weaker when such institutions are themselves weak.

The second experiment concerns attracting external entrepreneurs to invest in the region (Fig. 4(b)). This could be done, for example, with lump-sum incentives. In this case, the policy is a temporary one, lasting only five periods. The policy is now applied to three regional cases, which are all at the same level of starting GDP $(100 \%)$ but are different in the mobility of firms, with one having higher firm birth and death rates, and the other having lower firm birth and death rates. As can be observed in the graph, this policy has a larger and more lasting impact in a region where firm mobility is lower, as the attraction of new entrepreneurs discourages the incumbent ones less.

Even if it is not possible to show many simulations for reasons of space, every policy or combination of policies has a different impact in the model, depending on the starting regional situation. This makes the instrument fully place-based, i.e., in line with recent theories which affirm that policies have to be tailored to each region.

\section{CONCLUSIONS}

In an era in which it is often suggested that regional policy should become increasingly place based (BARCA, 2009), ex-ante policy assessment needs new tools that can deal with the diversity of regional situations and, hence, can simulate the impact of policies in different regional contexts.

It is not just a matter of comparing different policies but also of considering whether the same policy has the same impact if implemented in different regions. The receptiveness to policies in fact varies significantly with the level of the institutions present in the region, the type of economic agents living there and the type of economic activities present. To use a term that is becoming increasingly diffuse, one could say that the receptiveness to policies is linked to the level of territorial capital, which is changing but only through very slow processes. Also important are the composition of territorial capital and the typology of the policies being implemented. Territorial capital has many facets, and these can act as catalysts for different regional policies, with each territorial capital asset being able to expand the impact of some types of policies.

This paper has proposed one tool to assess ex-ante place-based policies, a simulation evolutionary economic geography model showing the flows of knowledge within a region and between the region and external regions. This model implements a refined linear innovation model, adding to that the recent idea that spillovers do not just take place by pure proximity but generally through the movements of specific groups of people, such as entrepreneurs or researchers (BRESCHI and Lissoni, 2009). A simulation methodology is useful because it allows a representation of the complexity of theoretical arguments without oversimplification, and at the same time allows the sound testing of theoretical hypotheses. Moreover, a simulation approach allows modelling of interrelation and recursiveness.

The model developed in this paper is built upon three stocks of knowledge - regional internal knowledge, shared knowledge and external knowledge which allow a representation of interregional knowledge flows. Within a region there is another process in which knowledge is used to generate patents, which, in turn, can be used to invent new products. All these mechanisms are made possible by the presence of the most relevant economic agents, i.e., basic and applied researchers, firms/entrepreneurs and qualified workers.

The model was calibrated on an average NUTS-2 European region, this being the standard unit of policy decision for European cohesion policy. This allows a comparison of the magnitude and time delay of a number of possible policy interventions. It is important 
to understand the time dynamics of policies before implementing them, so that the impacts of both conjunctural and structural policies can be considered in different cases. By modelling different regional situations through different parameters of the model, the paper has also shown that, as advocated by the theorists of the place-based approach, the same policy can have very different impacts in different contexts.

The next step in the research is the adaptation and application of the model to a specific region. This requires calibration on actual data, and most likely extensive fieldwork carried out with a public administration, which makes this step challenging enough to be pursued as a separate stage. The result of this next step will be a useful ex-ante appraisal tool for policymakers, who will be able to compare the impact of different policies in their territories. The framework is general enough to be extended to analyse sector-specific policies or to disaggregate regional institutions. The final aim is to facilitate better competitiveness and innovation policies more suited to the characteristics of the regions to which they are applied.
Disclosure statement - No potential conflict of interest was reported by the author.

Supplemental data - Supplemental data for this article can be accessed at http://10.1080/00343404.2015.1068930

\section{NOTES}

1. For simplicity, this paper considers 'basic researchers' to be primarily involved in the creation of knowledge, and 'applied researchers' in the patenting process, even if interactions between the two do exist and it is likely that both types of researchers produce both outputs, even if to different extents.

2. Stochasticity is handled in the model by making random rather than deterministic (with the same mean and a realistic variance) efforts in relation to processes such as patenting, but this is to move a little too far from this paper's focus on policies.

3. The choice of a region instead of a functional urban area was discussed in the second section.

4. A previous, intermediate, step of the research includes the detail of the actual sources and values used (FrATESI, 2014a)

\section{REFERENCES}

Andersson Å. E. (1986) The four logistical revolutions, Papers in Regional Science 59, 1-12. doi:10.1111/j.1435-5597.1986. tb00978.x

Arthur W. B. (1994) Increasing Returns and Path Dependence in the Economy. University of Michigan Press, Ann Arbor, MI.

Asheim B., Cooke P. and Martin R. (Eds) (2006) Clusters and Regional Development: Critical Reflections and Explorations. Routledge, London.

Audretsch D. B. and Feldman M. P. (1996) R\&D spillovers and the geography of innovation and production, American Economic Review 86, 630-640.

Audretsch D. B. and Feldman M. P. (2004) Knowledge spillovers and the geography of innovation, in Henderson J. and Thisse J. (Eds) Handbook of Regional and Urban Economics, pp. 2713-2739. North Holland, Amsterdam.

Balconi M., Brusoni S. and Orsenigo L. (2010) In defence of the linear model: an essay, Research Policy 39, 1-13. doi:10.1016/j. respol.2009.09.013

Barca F. (2009) An Agenda for a Reformed Cohesion Policy: A Place-Based Approach to Meeting European Union Challenges and Expectations. Independent Report prepared at the request of Danuta Hübner, Commissioner for Regional and Urban Policy, European Commission.

Barca F., McCann P. and Rodríguez-Pose A. (2012) The case for regional development intervention: place-based versus placeneutral approaches, Journal of Regional Science 52, 134-152. doi:10.1111/j.1467-9787.2011.00756.x

Barkley Rosser J. (2011) Complex Evolutionary Dynamics in Urban-Regional and Ecologic-Economic Systems: From Catastrophe to Chaos and Beyond. Springer, Berlin.

Batten D. and Johansson B. (1987) Dynamics of metropolitan change, Geographical Analysis 19, 189-199. doi:10.1111/j.15384632.1987.tb00124.x

Boschma R. and FrenKEN K. (2006) Why is economic geography not an evolutionary science? Towards an evolutionary economic geography, Journal of Economic Geography 6, 273-302. doi:10.1093/jeg/lbi022

Boschma R. A. and Lambooy J. G. (1999) Evolutionary economics and economic geography, Journal of Evolutionary Economics 9, 411-429. doi:10.1007/s001910050089

Braczyk H. J., CoOke P. and Heidenreich M. (Eds) (1998) Regional Innovation Systems. UCL Press, London.

BresChi S. and Lissoni F. (2001) Localised knowledge spillovers vs. innovative milieux: knowledge 'tacitness' reconsidered, Papers in Regional Science 80, 255-273. doi:10.1007/PL00013627

BRESCHI S. and LISSONI F. (2009) Mobility of skilled workers and co-invention networks: an anatomy of localized knowledge flows, Journal of Economic Geography 9, 439-468. doi:10.1093/jeg/lbp008

CAmAGni R. (2009) Territorial capital and regional development, in CAPEllo R. and NijKAmP P. (Eds) Handbook of Regional Growth and Development Theories, pp. 118-132. Edward Elgar, Cheltenham.

Capello R. (2007) Regional Economics. Routledge, London.

Capello R. and Lenzi C. (2015) Knowledge, innovation and productivity gains across European regions, Regional Studies, 49 (11). doi:10.1080/00343404.2014.917167

Crescenzi A. and Rodríguez-Pose A. (2011) Innovation and Regional Growth in the European Union. Springer, Berlin. 
Dixon R. and ThiRlwall A. P. (1975) A model of regional growth rate differences on Kaldorian lines, Oxford Economic Papers 27, $201-214$. Edquist C. (Ed.) (1997) Systems of Innovation: Technologies, Institutions and Organizations. Pinter, London. European Commission (2010) Europe 2020: A European Strategy for Smart, Sustainable and Inclusive Growth. 3 March, COM(2010) 2020. European Commission, Brussels.

Fagerberg J. (2005) Innovation: a guide to the literature, in Fagerberg J., Mowery D. C. and Nelson R. R. (Eds) The Oxford Handbook of Innovation, pp. 1-26. Oxford University Press, Oxford.

Fischer M. and Nijkamp P. (2009) Entrepreneurship and regional development, in Capello R. and Nijkamp P. (Eds) Handbook of Regional Growth and Development Theories, pp. 182-198. Edward Elgar, Cheltenham.

Fratesi U. (2008) Regional policy from a supra-regional perspective, Annals of Regional Science 42, 681-703. doi:10.1007/ s00168-007-0167-x

FRATESI U. (2010) Regional innovation and competitiveness in a dynamic representation, Journal of Evolutionary Economics 20, 515552. doi:10.1007/s00191-009-0169-1

Fratesi U. (2014a) Simulating the impact of regional innovation policies with a dynamic model of regional knowledge flows, in

Patrucco P. P. (Ed.) The Economics of Knowledge Generation and Distribution: The Role of Interactions in the System Dynamics of Innovation and Growth, pp. 252-271. Routledge, Abingdon.

Fratesi U. (2014b) Editorial: The mobility of high-skilled workers - causes and consequences, Regional Studies 48, $1587-1591$. doi:10.1080/00343404.2014.955689

Gilbert N. and Doran J. (Eds) (1994) Simulating Societies. UCL Press, London.

Haken H. (1983) Synergetics, Nonequilibrium Phase Transitions and Social Measurement, 3rd Edn. Springer, Berlin.

HAKen H. (1985) Synergetics - an interdisciplinary approach to phenomena of self-organization, Geoforum 16, 205-211. doi:10. 1016/0016-7185(85)90029-6

Hollanders H., Tarantola S. and LoschKy A. (2009) Regional Innovation Scoreboard (RIS) 2009.

JohansSon B. (1993) Economic evolution and urban infrastructure dynamics, in ANDersson Å. E., Batten D. F. Kobayashi K. and Yoshikawa K. (Eds) The Cosmo-Creative Society, pp. 151-175. Springer, Berlin.

Johansson B., Karlsson C. and Stough R. (2001) Theories of endogenous regional growth - lessons for regional policies, in Johansson B., Karlsson C. and Stough R. (Eds) Theories of Endogenous Regional Growth - Lessons for Regional Policies, pp. 406-414. Springer, Berlin.

Kaldor N. (1970) The case for regional policies, Scottish Journal of Political Economy 17, 337-348. doi:10.1111/j.1467-9485.1970. tb00712.x

Kogler D. F. (2015) Editorial: Evolutionary economic geography - theoretical and empirical progress, Regional Studies 49, 705711. doi:10.1080/00343404.2015.1033178

Leydesdorff L. and Etkowitz H. (1998) The triple-helix as a model for innovation studies, Science and Public Policy 3, $195-203$. Lundvall B.-A. (Ed.) (1992) National Systems of Innovation. Pinter, London.

MoEn J. (2005) Is mobility of technical personnel a source of R\&D spillovers?, Journal of Labor Economics 23, 81-114. doi:10.1086/ 425434

Myrdal G. (1957) Economic Theory and Underdeveloped Regions. Duckworth, London.

Nelson R. R. (Ed.) (1993) National Innovation Systems: A Comparative Analysis. Oxford University Press, Oxford.

Nelson R. R. and Rosenberg N. (1998) Science, technological advance and economic growth, in Chandler A. D. Jr, Hagstrom P. and Solvell O. (Eds) The Dynamic Firm: The Role of Technology, Strategy, Organisations and Regions. Oxford University

Press, Oxford.

Nelson R. R. and Winter S. G. (1982) An Evolutionary Theory of Economic Change. Harvard University Press, Cambridge, MA.

Organisation for Economic Co-operation and Development (OECD) (2011) Regions and Innovation Policy. OECD Reviews of Regional Innovation. OECD, Paris.

Polanyi M. (1969) Knowing and Being, ed. and intro. by Grene M. University of Chicago Press, Chicago, IL.

Richardson H. W. (1978) Regional Economics. University of Illinois Press, Urbana, IL.

Rodríguez-Pose A. (1999) Innovation prone and innovation averse societies: economic performance in Europe, Growth and Change 30, 75-105. doi:10.1111/0017-4815.00105

RodríGUEZ-Pose A. (2001) Is R\&D investment in lagging areas of Europe worthwhile? Theory and empirical evidence, Papers in Regional Science 80, 275-295. doi:10.1007/PL00013631

Rosenberg N. (1982) Inside the Black Box: Technology and Economics. Cambridge University Press, Cambridge.

Sterlacchini A. (2008) R\&D, higher education and regional growth: uneven linkages among European regions, Research Policy 37, 1096-1107. doi:10.1016/j.respol.2008.04.009

UsAI S. (2011) The geography of inventive activity in OECD regions, Regional Studies 45, 711-731. doi:10.1080/ 00343401003792492

Varga A. (Ed.) (2009) Universities, Knowledge Transfer and Regional Development: Geography, Entrepreneurship and Policy. Edward Elgar, Cheltenham.

Wolstenholme E. F. (1990) System Enquiry. Wiley, Chichester. 